\title{
Scenario Planning in Disaster Management: A Call to Change the Current Practice
}

\author{
Sharafaldeen Bin Nafisah
}

\begin{abstract}
The current pandemic uncovered how disastrous our disaster plans. The disaster doctrine in its current state is far from ideal, and another model of thinking is warranted. Scenario planning provides a standardised way of thinking on how to plan for the future. We believe disaster doctrine is probably the most doctrine that will benefit from this thinking model. Using scenario planning will uncover our assumptions, deficiencies and will inform a disaster best practice.
\end{abstract}

Index Terms-Scenario Planning, Disaster Management, Planning for Crises, Disaster Strategy

\section{INTRODUCTION}

Uncertainty, turbulence and unpredictable response arecharacteristics of every disaster event. Effective management of such disasters requires a movement beyond the social order disruption [1] to planning for a new order and a new norm. In this article, we aim to explore the effect of scenario planning in disaster management and advocate another look at how disasters could be managed differently.

\section{PLANNING FOR THE FUTURE}

Planning for disasters requires formulating scenarios for the future. It is prudent to assert that scenario planning is not forecasting [1], and planners should not be blamed for not foreseeing the pandemic, for instance. Still, they should be blamed for not exploring pandemic scenarios with a high dissemination rate. Interestingly the CDC published different viral transmissibility scenarios with a speculated impact under each scenario [3]. Those descriptive scenarios are not helpful unless we build from them containment strategies.

It takes time and effort to prepare for the future, yet more time and efforts will be lost if those plans were underdeveloped. Building scenarios trigger an understanding of our current deficiencies in planning. However, it does not mean raising the level of preparedness to as if a nuclear power plant reactor failure will occur tomorrow, but to have clear plans that even if the atomic accident occurs today, its impact will be minimal.

\section{UNDERLYING ASSUMPTIONS AND FRAMES}

Exploring options for the future often expose our current assumptions [4]. Assumptions are disastrous if it minimises the impact of highly catastrophic events or underestimates a highly probable event. Using the methodology of reframing will uncover other scenarios that might be evident during the scenario generation phase. Hence, such planning triggers organisational learning and will also trigger the construction of other scenarios in other contexts. The disaster of the explosion of the port of Beirut of august 2020 is an unfortunate example.

Sharafaldeen Bin Nafisah is with Emergency Department, King Fahd Medical City, Saudi Arabia., e-mail: dr.sharafaldeen@yahoo.com
The blast resulted from a large amount of nitrates abandoned in the port [5]. The political uncertainty, the turbulence around the country's borders, and the economic crises escalate the impact of the forthcoming disaster to a higher level.

What might happen if the policymakers of Al-Hussein New Salt Hospital used scenario planning to consider the possibility of oxygen reservoir failure during the current pandemic [6]. The same scenario recurred in Al-Husseiniya hospital in Egypt [7]. How many people could be saved? Those events uncover the lack of the "inherent human capacity for imagining futures to understand the present situation better and to identify possibilities for new strategy" [4]. Considering the likelihood of crises should at least trigger proactive thinking of solutions which is enough for less probable events. Planning for possible manmade disasters, earthquakes, or even a tsunami might uncover the pending catastrophe of the nitrates in the port. The discovery process will result from immersive thinking that overcomes the narrow thinking of planning for "a specific event within a particular place and within a particular time frame". Unfortunately, judging our anchor and assumptions needs outsiders that are not influenced by our unconscious understanding of who we are, where we are, and what are we doing.

\section{WHO SHOULD DO DISASTER SCENARIO PLAN- NING \\ Challenging what we believe is a mission never been} easy and acceptable. Putting aside the decision biases and heuristics, it is well known that our perspective gets narrower once we emerge into a specific situation. Planning for the unplanned requires another perspective.

The complexity of the disaster in the hospital and the community calls for involving different mindsets. Disaster doctrine is of interest in those with disaster medicine degree, disaster managers, emergency physicians, paramedics, nursing, risk managers, executives, policymakers, not to mention the media, operational section, finance, etc. Nonetheless, not all of those are involved in training drills. Even then, short-lived training like drills might not inform a strategic foresight for the future. It is for the drills manager or the commander to inform the process and to include what he/she noted as a deficiency or needed improvement. This is not ideal, and the outcome will inform only the same drill in the future because discussion beyond the drill's introduced variable is often lacking.

In the oxford scenario planning program, designing one of the scenarios for an X European company, the planners introduced several contextual factors for the fate of its funding, considering the rise of populist, the closed nation borders, artificial intelligence disruption and when the truth is repeatedly undermined. This level of thinking is innovative and has 
not been introduced into the disaster doctrine. Establishing a scenario planning unit as part of the command centre of the disaster could not be emphasised further, and its urgency stems from the chaos of our plans in this relentless pandemic. The lack of planning has led to copying plans from other settings, and given the context-specific plans, those might not be designed to succeed outside its contextual factors. If such knowledge were incorporated into disaster plans prior to this pandemic, perhaps we would not be wearing masks while writing this article.

\section{SOURCES OF INFORMATION}

Disaster research lies upon past information to shape the future response. Such an approach has two deficiencies; first, the absence of the previous impact makes forecasting less likely, albeit it crosses the mind. Second, even if there is a prior experience with a similar event, it does not guarantee organisational learning that ensures a better future response. Ideally, if learning occurs, we need all types of disaster that happened, studied thoroughly, and led to organisational learning. Furthermore, disasters outside the context make organisational learning less likely, especially when learning points are not shared academically or as part of professional institutions. The last point is also augmented by the lack of success in dealing with those disasters, discouraging planners from sharing their failed efforts. Scenario planning overcomes those deficiencies as it plans for disasters that occurred and that ought to occur.

Another source of information is mathematical models $[8,9]$. Some of those models map the social interactions between individuals based on a specific "expected" logarithmic model of interaction and then measure the impact of disease transmissibility. Pessimistic models-we would imagine does not expect to receive any attention, albeit getting published. Nevertheless, the use of mathematical models is far from ideal in disaster discipline. Those models do not take all of the contextual factors that might influence how people behave and the economic impact, the faster the response, and the uncertainty of the improvised public policies. In alignment with that, critics of laboratory simulations argued that those were deficient in simulating the complexity of the disasters in the real world [10]. However, using such I.T. systems, when coupled with the beauty of the human mind in building scenarios for the future, will yield a model of excellence. Planners ought to take from those models the impact and explore determinants for every excellent and worst-case scenario and then plot the response in the form of practical strategies.

We believe other tools are also valuable in designing scenarios, including drills. We should assert that drills should not be underutilised; instead, those are valuable tools to test scenarios and inform further scenario plans. Qualitative data from those drills and quantitative data will inform policymakers how much they should invest in this scenario compared to other scenarios. Those data will provide information on the cost of the events, the number of deaths, morbidity, infection rate, vulnerability and disability, among others. It might also inform the policymakers on how much to invest in scenarios compared to other proposed projects.

\section{CONTINUOUS LEARNING}

The beauty of scenario planning is that it fosters an environment of continuous learning [11,12]. This is relevant to disaster doctrine in which data is collected during the events to inform subsequent action. Planning before receiving such data will always inform better decision making simply because we already controlled for other contextual factors. Not only that, but it will also reduce the situational bias that we tend to fall into unconsciously. This learning model will improve the disaster command response in any particular geographical region affected by similar contextual factors.

Nonetheless, the success of such organisational learning will need a proactive, engaging setting. i.e., drawing attention to scenarios written several years ago is never a plan, and surely not "planning". Engaging with existing scenarios on a multilevel managerial role that is continuously ameliorated and enhanced will make its applications -when needed- a matter of routine. It will not provide the relaxation of the drills, nor its manufactured surprise, but rather, a sense of control.

A shared understanding between different policymakers' level is crucial for the success of the institutions and the country. A shared sense of the future justifies and legitimise action in the present. Here, we believe scenario planning takes a broader view of a disaster than drills in which managers are using shared frames of what they should do now. Securing funds, fostering collaborations, coalition and performance enhancement will result from such shared understanding. Assumptions of the future will also be shared, and what is appropriate for disaster manager will also be perceived as necessary for executives. New insight about the need for a coalition with specific institutions, for instance, may trigger current initiatives to collaborate. Using scenario planning may uncover new stakeholders, new opportunities and new partnership.

\section{MEASURING SUCCESS}

In disaster management, the success of the response is erroneously related to how fast people act. Perhaps getting away with an inefficient act is easy, given that the event itself will be blamed. An important question might arise on how to measure the success of those scenario planning? Scenarios that enforce taking proactive strategies will delineate timely action as well as an efficient act.

It is crucial to assert that the occurrence of those scenarios is not the endpoint for measuring its success. Instead, it is how we perceive the future from here. The success of the designed scenarios lies in its tangible change of the current ghost scenario. The openness to outside scenarios is always a measure of success as it reflects the willingness to change. Nonetheless, the lack of existing disaster scenarios with specific outcome measures will make the success of any disaster plan ambiguous. Take, for example, a flood from pipeline failure in hospital A. A multidisciplinary team responded, then the pipeline fixed in twenty minutes, and three patients were evacuated. In a similar situation in another hospital, hospital $\mathrm{B}$, ten patients were evacuated within ten minutes, and one patient had his ventilator disconnected but managed promptly. The success of those containments varies greatly, but both hospitals reported their action to be successful. The lack of outcome measures will make the first and second evet similar 
in success.

Avoiding the trap of "faster recovery", scenario planning takes time and allows more time for exploring efficiency. Planners ought to plan for faster achievement of site-specific recovery, with attention toward formulating policies and procedures for subsequent scenarios. The variable responses to disasters can only be formalised by standardising our learning points to other institutions, establishing a centralised body of the response that delineates the reporting system's cascade and accountability.

\section{FUTURE DIRECTION}

Overall scenario planning provides a standardised way of thinking on how to plan for the future. We believe disaster doctrine is probably the most doctrine that will benefit from this thinking model. Using scenario planning in such a field will move the current body of knowledge from the traditional "warning, evacuation, impact, and response and recovery period" into a more holistic approach to saving those in need and protecting the future.

\section{REFERENCES}

[1] Noji E. Public health consequences of disasters. Prehosp Disaster Med 2000; 15: 147-157."

[2] Schoemaker, P. J. H. 2008. Forecasting and Scenario Planning: The Challenges of Uncertainty and Complexity. Blackwell Handbook of Judgment and Decision Making, 274296. https://doi.org/10.1002/9780470752937.ch14

[3] Healthcare Workers. 2020. Centers for Disease Control and Prevention. https://www.cdc.gov/coronavirus/2019-ncov/h cp/planning-scenarios.html, accessed in Jan $5^{\text {th }} 2021$.

[4] Ramirez, R., \& Wilkinson, A. 2018. Strategic Reframing: The Oxford Scenario Planning Approach (Reprint ed.). Oxford University Press.

[5] Devi S. 2020. Lebanon faces humanitarian emergency after blast. Lancet (London, England), 396(10249), 456. https ://doi.org/10.1016/S0140-6736(20)31750-5

[6] Seven COVID patients die after oxygen fails at Jordan hospital. 2021. Arab News. https://www.arabnews.com/node/ 1824776/middle-east, accessed Jun 10th 2021.

[7] Anger in Egypt after death of coronavirus patients due to "oxygen shortage." 2021. EgyptToday. https:/www.egyptt oday.com/Article/1/96043/Anger-in-Egypt-after-death-of-coro navirus-patients-due-to, accessed Jun 10th 2021.

[8] Brandeau, M. L., McCoy, J. H., Hupert, N., Holty, J. E., \& Bravata, D. M. 2009. Recommendations for Modeling Disaster Responses in Public Health and Medicine: A Position Paper of the Society for Medical Decision Making. Medical Decision Making, 29, 438-460. https://doi.org/10.1177/02729 89x09340346

[9] Koenig, K. L. 2016. Koenig and Schultz's Disaster Medicine: Comprehensive Principles and Practices (2nd ed.). Cambridge University Press.

[10] Drabek TE, Haas JE. 1969. Laboratory simulation of organisational stress. Am Sociol Rev; 34: 223-238.

[11] Chermack, T. J., Lynham, S. A., \& van der Merwe, L. 2006. Exploring the relationship between scenario planning and perceptions of learning organization characteristics. Futures, 38(7), 767-777. doi:10.1016/j.futures.2005.12.010

[12] Haeffner, M, D Leone, L Coons, and $\mathrm{T}$ Cher- mack. 2012. The effects of scenario planning on participant perceptions of learning organization characteristics. $\mathrm{Hu}-$ man Resource Development Quarterly, 23(4), 519-542. DOI: $10.1002 / \mathrm{hrdq} .21147$ 